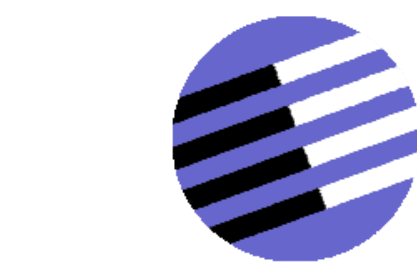

GOVERNANCE AND THE EFFICIENCY

OF ECONOMIC SYSTEMS

CESY

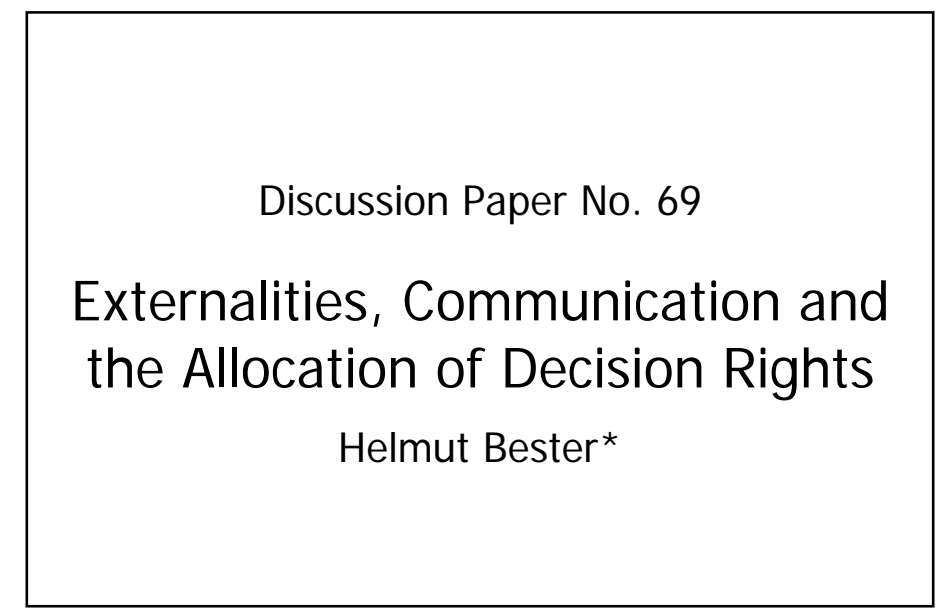

November 2005

*Helmut Bester, Free University Berlin, Dept. of Economics, Boltzmannstr. 20, D-14195 Berlin, Germany. hbester@wiwiss.fu-berlin.de

Financial support from the Deutsche Forschungsgemeinschaft through SFB/TR 15 is gratefully acknowledged.

Sonderforschungsbereich/Transregio $15 \cdot$ www.gesy.uni-mannheim.de 


\title{
Externalities, Communication and the Allocation of Decision Rights
}

\author{
Helmut Bester
}

November 18, 2005

\begin{abstract}
This paper views authority as the right to undertake decisions that impose externalities on other members of the organization. When only decision rights can be contractually assigned to one of the organization's stakeholders, the optimal assignment minimizes the resulting inefficiencies by giving control rights to the party with the highest stake in the organization's decisions. Under asymmetric information, the efficient allocation of authority depends on the communication of private information. In the case of multiple decision areas, divided control rights may enhance organizational efficiency unless there exist complementarities between different decisions.
\end{abstract}

Keywords: Authority, Decision Rights, Externalities, Incomplete Contracts, Imperfect Information, Theory of the Firm

JEL Classification No.: D23, D82, L22, P14

*Free University Berlin, Dept. of Economics, Boltzmannstr. 20, D-14195 Berlin, Germany. Email address: hbester@wiwiss.fu-berlin.de. Support by the German Science Foundation (DFG) through SFB/TR 15 is gratefully acknowledged. I wish to thank Dominique Demougin, Martin Hellwig, Roman Inderst, Daniel Krähmer, Benny Moldovanu, Marco Pagano, Roland Strausz and two referees for discussions and helpful comments on this paper and its predecessor Bester (2002). 


\section{Introduction}

The most important decisions in an organization affect not only the decision maker but also other members of the organization. The decision maker therefore exerts an externality on other stakeholders of the organization. This point is already observed by Simon (1951, p. 302) who notes that in the employer-worker relationship

"the worker has no assurance that the employer will consider anything

but his own profit in deciding what he will ask the worker to do."

Because the party holding the decision right will opportunistically select a decision in its own interest, it will typically fail to internalize the concerns of other stakeholders.

In a world of complete contracts, the members of an organization could simply write a comprehensive contract to implement those decisions that maximize their joint surplus. In line with the Coase Theorem, the benefits and costs of the different members would be fully internalized by monetary transfers under the organization's compensation scheme. Yet, as Grossman and Hart (1986), Hart and Moore (1990) and Hart (1995) point out, it is typically impossible to specify all the organization's future decisions in advance in a legally binding way. This is so because the details of different decisions are often not verifiable to outsiders and the courts or prohibitively costly to specify ex ante.

In this paper, we follow Aghion et al. (2002) and Holmstrom and Hart (2002) by assuming that only decision rights are contractible ex ante, because decisions are neither ex ante nor ex post verifiable. In Section 2 we consider two agents who jointly undertake a project. In addition to specifying a monetary transfer, a contract assigns the authority over project related decisions to one of the agents. The agents' stakes in the project can be identified with their willingness-to-pay for obtaining the control right. Under an efficient contract, it is the agent with the highest valuation of authority who will control the project. This insight allows us to determine easily the optimal governance structure in various environments. For example, in the employer-worker relationship it is indeed efficient that the employer controls the firm as long as decisions have a higher impact on the firm's revenue than on the worker's disutility of work.

In Section 3 we extend our basic model by introducing asymmetric information. For instance, the employer and the worker may have private information about how the adoption of a new technology affects the firm's revenue and the disutility of work, respectively. We identify several situations in which truthful revelation of private information can be induced without generating an efficiency loss. This is possible through a mechanism which uses 'externality payments', similar to those that implement the efficient provision of a public good under imperfect information. In our framework, however, monetary incentives are only one part of the elicitation 
mechanism. They are complemented by making also the allocation of authority contingent on revealed information. It is easy to see why this must be so. Suppose for example that in some information states the adoption of a new technology raises the employer's revenue only slightly whereas it imposes a major effort cost on the worker. In these states, efficiency dictates that the employer transfers the decision right over the adoption to the worker.

In Section 4 we consider multiple decision problems so that control rights in different areas of the organization may be divided between different parties. This framework allows us analyze to what extent the same agent should exert centralized authority over several areas. On the one hand, complementarities between decisions are shown to favor centralized rather than decentralized decision rights. On the other hand, divided control rights limit the excessive power of a single party and may enable the implementation of a compromise between extreme decisions. Indeed, centralized authority will typically not lead to a first-best outcome because decisions are not even ex post contractible so that inefficiencies cannot be negotiated away. But we are able to show that the first-best can be supported by the appropriate allocation of authority if each decision problem consists of a choice between two alternatives, like "yes" or "no". Such binary decisions occur e.g. in Aghion et.al. (2004) and in Hart and Holmstrom (2002). Our observation that they allow achieving the first-best suggests that efficiency gains may be obtained by a governance structure that splits the overall decision process into several sub-decisions. We illustrate this point in a simple two-stage decision process where the decision maker in the first stage restricts the action set available to the controlling stakeholder in the second decision stage (cf. Tirole (1999, p. 31)).

Our analysis of the allocation of power in organizations does not necessarily associate control rights with the ownership of assets.11 This differs from the propertyrights theory of the firm developed by Grossman and Hart (1986), Hart and Moore (1990) and Hart (1995), where control rights are identified with property rights and generate incentives for relationship-specific investments. Yet, in organizations where the owner of an asset is entitled to dictate certain decisions, an "asset might simply be a 'decision right' and ownership might simply mean 'control'" (Gibbons 2005, p. 210). Thus the optimal allocation of decision rights can easily be translated into a theory of asset ownership. This approach is used in Hart and Holmstrom (2002), who develop a theory of firm scope by investigating whether integration or non-integration between two production units is the optimal organizational form. They assume that "ownership of a unit confers the right to make the decisions in that unit" and so "changes in ownership are the only way to affect how decisions are made and how well they take into account external effects" (p. 2).

\footnotetext{
${ }^{1}$ As already Berle and Means (1932) point out, control rights and ownership may indeed be separated: In corporations typically the managers rather than the shareholders hold most of the decision rights.
} 
Our analysis of asymmetric information in Section 3 is related to Dessein (2002) who considers the optimal assignment of authority in a principal-agent model where the agent has private information. An important difference between his model and our analysis is that we allow for monetary transfers. For the preference structure used by Dessein (2002) we can show that with transfers it becomes possible to implement the same decisions as under symmetric information. Finally, the subject of this paper is related to Aghion and Tirole's (1997) model, in which authority affects the incentives to invest in information gathering. Such ex ante investments play no role in our analysis; in Section 3 we focus on contracting between agents who are exogenously endowed with private information.

The remainder of this paper is organized as follows. Section 2 provides a basic framework to study the efficient allocation of authority when decisions generate externalities on other members of the organization. In Section 3 we extend this framework by assuming that payoffs and preferences over decisions are private information. Section 4 considers multiple decision areas, which allow for divided control rights. Finally, Section 5 contains concluding remarks. The proofs of all formal propositions are relegated to an appendix.

\section{Efficiency and Authority}

We consider two agents, $i=1,2$, who derive benefits or incur costs from a joint project. These payoffs depend on a decision $d \in D$ that specifies the details of the project such as e.g. its scale, its riskiness, or the quality of inputs and outputs. We assume that the agents can exchange monetary payments and denote by $w$ a transfer from agent 1 to agent 2 . Note that $w$ may be negative, in which case effectively agent 2 makes a payment to agent 1. The net payoffs of the two agents depend on the decision $d$ and the transfer $w$ according to

$$
u_{1}(d)-w, \quad u_{2}(d)+w .
$$

The agents' utility functions are commonly known; but the realized payoffs $u_{1}(d)$ and $u_{2}(d)$ are not publicly observable. ${ }^{2}$ Since the agents have quasi-linear utilities, their payoffs are transferable and so the joint surplus from decision $d$ is

$$
S(d) \equiv u_{1}(d)+u_{2}(d)
$$

The agents are unable to contractually specify decisions in a legally binding way. The usual justification for this assumption is that decisions are not verifiable to outsiders and hence not enforceable by the courts. Also, it may be too costly to describe decisions with all their detail in a written contract. It is, however, possible

\footnotetext{
${ }^{2}$ See Bester (2002) for an environment where one of the agent's payoff is imperfectly observable.
} 
to delegate the decision right contractually to one of the agents.$^{3}$ This means that this agent receives the authority to select his most preferred decision. The allocation of authority may be enforced by the access to the assets and resources that are necessary to implement a decision $\sqrt[4]{4}$

In addition to the decision right, monetary transfers are contractible. Notice that transfers cannot depend explicitly on $d$ or $u_{1}(d)$ and $u_{2}(d)$, because these variables are not verifiable. Thus a contract is described by $\gamma=(h, w)$, where $h \in\{1,2\}$ denotes the agent who is entitled to choose $d$. In what follows, we denote by

$$
d^{i} \equiv \operatorname{argmax}_{d \in D} u_{i}(d)
$$

the most preferred decision of agent $i$ and assume that it is uniquely defined. Of course, the allocation of authority becomes interesting only if $d^{1} \neq d^{2}$, i.e. if the two agents have conflicting interests. Since the party who holds the decision right will choose its preferred decision, the payoffs from a contract $\gamma=(h, w)$ are

$$
U_{1}(\gamma) \equiv u_{1}\left(d^{h}\right)-w, \quad U_{2}(\gamma) \equiv u_{2}\left(d^{h}\right)+w
$$

Obviously, given the contractual constraints, the agents will select a contract that is not pareto-dominated, i.e. a contract that is (second-best) efficient in the following sense:

Definition A contract $\gamma$ is efficient if there is no other contract $\gamma^{\prime}$ such that $U_{1}\left(\gamma^{\prime}\right) \geq U_{1}(\gamma)$ and $U_{2}\left(\gamma^{\prime}\right) \geq U_{2}(\gamma)$, with strict inequality for some $i \in\{1,2\}$.

Of course, the actual selection of a contract will depend also on the agents' relative bargaining power and their outside options.5 $5^{5}$ In what follows, we ignore such factors because they affect only the distribution of surplus via the transfer $w$ and not the allocation of authority.

The agent who holds the decision right selects $d$ according to (3), ignoring the external effects of his decision on the other agent's utility. Clearly, it is beneficial not to be exposed to such effects from the other agent's decision behavior. Agent

\footnotetext{
${ }^{3}$ Note that the assignment of decision rights differs from the task assignment problem (see e.g. Holmstrom and Milgrom (1991)) because in the latter problem the agent who becomes responsible for a task also bears the cost of performing this task. In our model the decision maker may affect the other agents' payoffs from performing their task.

${ }^{4}$ Rather than by an explicit contract, the allocation of authority may also be supported implicitly as a self-enforcing agreement in a repeated interaction, cf. Baker et. al. (1999) and Bolton and Rajan (2000).

${ }^{5}$ Implicitly, we assume that neither party can credibly threaten to quit the project after a decision has been made. Also, we ignore wealth constraints, which impose restrictions on the transfer $w$ and may affect the allocation of decision rights; see Aghion and Rey (2003) and Puschke (2005).
} 
i's valuation of authority

$$
v_{i} \equiv u_{i}\left(d^{i}\right)-u_{i}\left(d^{j}\right), \quad i \neq j,
$$

measures his benefit from having the authority over decisions. To obtain the decision right from the other agent, agent $i$ is willing to pay an amount of up to $v_{i}$. Clearly, this amount is positive whenever $d^{i} \neq d^{j}$.

If $v_{i}>v_{j}$, then agent $i$ has a higher stake in controlling the joint project and so he should efficiently have the authority over project decisions:

Proposition 1 A contract $\gamma=(i, w)$, which assigns the decision right to agent $i$, is efficient if and only if $v_{i} \geq v_{j}$. Equivalently, $\gamma=(i, w)$ is efficient if and only if $S\left(d^{i}\right) \geq S\left(d^{j}\right)$.

Proposition 1 indicates that the decision right should be allocated to the party whose payoffs depend more sensitively on decisions. In the following example, agent 1 owns the assets of a firm and agent 2 is an employee. In a world of complete contracts it does not make a difference whether the capitalists hire workers or whether the workers hire capitalists. Yet, it does make a difference who controls the firm when decisions are not contractible. In line with Proposition 1, the capitalist should be endowed with the control right as long as decisions are more important for the firm's output than for its labor input.

EXAmple 1 Project $d \in D=\{A, B\}$ generates the gross return $x_{d}>0$ for agent 1 (the firm owner) and the disutility of work $e_{d}>0$ for agent 2 (the employee). Let

$$
u_{1}(A)=x_{A}>u_{1}(B)=x_{B}, \quad u_{2}(A)=-e_{A}<u_{2}(B)=-e_{B} .
$$

Thus $d^{1}=A$ and $d^{2}=B$. By Proposition 1, the firm owner has the authority to select the project if $x_{A}-x_{B}>e_{A}-e_{B}$.

By the second statement of Proposition 1, the optimal assignment of decision rights minimizes the inefficiencies that arise because of the incentive restrictions in (3). Yet, typically decision maker $i$ will implement only a second-best solution $d^{i}$. If decisions were directly contractible, the optimal contract would specify the first-best decision

$$
d^{*} \equiv \operatorname{argmax}_{d \in D} S(d),
$$

which maximizes the overall surplus from the project. When the agents have conflicting interests, their decision behavior reflects their own objectives rather than the organization's joint surplus. Yet, there is an interesting class of environments in which the efficient contract implements the first-best: This is the class of binary choice problems where $D$ contains only two alternatives. A typical example is the choice between "yes" or "no". 
Proposition 2 Let $D=\left\{d_{Y}, d_{N}\right\}$. Then a contract $\gamma=(h, w)$ is efficient if and only if it implements the first-best decision, i.e. $d^{h}=d^{*}$.

The intuition behind this observation is simply that at least one of the agents necessarily prefers the first-best decision over the alternative. Having the authority over the project, this agent will select the first-best. In general, this is no longer true when $D$ contains more than two elements. ${ }^{6}$ Yet, as we discuss in Section 4 below, Proposition 2 indicates that in more complex situations efficiency gains may be realized by breaking up the overall organizational problem into several binary sub-problems.

In the remainder of this section we consider an environment where $d$ is a continuous variable and the agents' payoffs are strictly concave: Let $D \equiv[\underline{d}, \bar{d}] \subset \mathbb{R}$ with $\underline{d}<\bar{d}$. Further, for $i=1,2, u_{i}: D \rightarrow \mathbb{R}$ is twice continuously differentiable with $u_{i}^{\prime}(\underline{d}) \geq 0, u_{i}^{\prime}(\bar{d}) \leq 0$ and $u_{i}^{\prime \prime}(\cdot)<0$. Within this differentiable framework, the notion of sensitivity towards changes in the decision variable can be made more precise. Agent $i$ 's valuation of authority, as defined by (5), may be expressed as

$$
v_{i}=\int_{d^{j}}^{d_{i}} u_{i}^{\prime}(d) \mathrm{d} d
$$

Since $u_{i}^{\prime}\left(d^{i}\right)=0$, the value of $v_{i}$ is positively related to the steepness of the marginal benefit $u_{i}^{\prime}$, i.e. the second derivative $u_{i}^{\prime \prime}$ of $u_{i}$. This insight provides the intuition for the following result:

Proposition 3 Let $\min _{d}\left|u_{i}^{\prime \prime}(d)\right|>\max _{d}\left|u_{j}^{\prime \prime}(d)\right|$. Then $v_{i}>v_{j}$ and so the contract $\gamma=(h, w)$ is efficient if and only if $h=i$.

The criterion of Proposition 3 becomes especially simple when the second derivatives of the agent's benefits are constant, i.e. if $u_{1}$ and $u_{2}$ are quadratic. Such payoffs are frequently used because of their computational simplicity. One prominent area is the mean-variance framework in the theory of finance where a quadratic payoff structure is helpful to derive optimal portfolio and investment decisions. The following example applies this framework to illustrate how the efficient allocation of authority may depend both on the project's riskiness and the agents' risk attitudes.

EXAMPLE 2 The two agents can jointly realize a risky investment. The set of decisions are the possible scales $d \in D=\mathbb{R}_{+}$of the project. A project of scale $d$ yields agent $i$ the return $d \tilde{X}_{i}$ where $\tilde{X}_{i}$ is distributed with mean $\mu_{i}$ and variance $\sigma_{i}^{2}$. Let agent $i$ 's expected payoff be represented by the mean-variance utility

$$
u_{i}(d)=\mu_{i} d-0.5 \rho_{i} \sigma_{i}^{2} d^{2},
$$

\footnotetext{
${ }^{6}$ See, for instance, Examples 2 and 7 .
} 
where $\rho_{i}$ is his coefficient of absolute risk aversion. It follows from Proposition 3 that the optimal allocation of authority over $d$ is independent of the mean returns $\left(\mu_{1}, \mu_{2}\right)$ : If $\rho_{1} \sigma_{1}^{2}>\rho_{2} \sigma_{2}^{2}$, agent 1 will take the investment decision $d$ under an efficient contract. Whether his decision will lead to under- or overinvestment relative to the first-best, depends also upon $\left(\mu_{1}, \mu_{2}\right)$. It is easily verified that $d^{1}<d^{*}$ if and only if $\left(\rho_{1} \sigma_{1}^{2}\right) /\left(\rho_{2} \sigma_{2}^{2}\right)>\mu_{1} / \mu_{2}$.

A simple measure of the divergence between the agents' objectives can be obtained by assuming that agent $i$ 's benefit depends on $d$ according to

$$
u_{i}(d)=\bar{u}_{i}-k_{i} \ell\left(\left|\theta_{i}-d\right|\right) \text {, }
$$

with $k_{i}>0$. The parameter $\theta_{i} \in D$ describes the agent's ideal decision and $\ell(\cdot)$ is a loss function with $\ell(0)=0, \ell^{\prime}(\cdot)>0$ and $\ell^{\prime \prime}(\cdot)>0$. Thus agent $i$ 's benefit is a decreasing function of the distance $\left|\theta_{i}-d\right|$ between the ideal and the actual decision. The distance $\left|\theta_{1}-\theta_{2}\right|$ represents then an (inverse) measure of how closely the agents' interests are aligned with each other.

If $\ell(\cdot)$ is quadratic, it follows immediately from Proposition 3 that an efficient contract will assign the decision right to the agent $i$ who puts a higher weight $k_{i}$ on his loss. The following result shows that this is the case even when the loss function is not quadratic. In particular, the congruence of interests and the agents' ideal decisions are irrelevant for the efficient allocation of the decision right.

Proposition 4 Let $u_{1}(\cdot)$ and $u_{2}(\cdot)$ satisfy (10). Further, suppose that $\theta_{1} \neq \theta_{2}$ and $k_{i}>k_{j}$. Then $v_{i}>v_{j}$ and so the contract $\gamma=(h, w)$ is efficient if and only if $h=i$.

To study information transmission in organizations, several authors $7^{7}$ have used the preference environment in (10) under the assumption that one of the agents is privately informed about his ideal project. The results in this section abstract from the presence of private information. But they will serve as a benchmark for the case of asymmetric information, which we consider in the following section.

\section{Asymmetric Information}

Information, which is important for the efficiency of choice, is often localized and dispersed within an organization. Typically, different members have access to different information. Their willingness to communicate their private information may

\footnotetext{
(2004).

${ }^{7}$ See e.g. Crawford and Sobel (1982), Dessein (2002), Krähmer (2004), Krishna and Morgan
} 
be stimulated by monetary incentives. But at least equally important is the allocation of control rights. This is so because the subordinates take into account how the decision maker reacts to the revelation of information. Their incentives to share information depend on whether this has positive or negative consequences for their own benefits. Therefore, communication incentives and the allocation of authority are interlinked. In fact, the optimal design of an organization may require the allocation of authority itself to be contingent on revealed information. In this section we show that such a transfer of control rights may facilitate the exchange of information 8

Studying the allocation of decisions rights under asymmetric information is complicated by the fact that the issue of authority becomes relevant only if decisions are not directly contractible. This means that contracts are necessarily incomplete. Therefore we cannot apply the standard Revelation Principle? which states that the range of implementable outcomes coincides with the set of outcomes that can be achieved through direct and truthful communication. This is so because this principle requires that the contracting parties can write a complete contract, which fully commits them to all future actions. If this prerequisite is not fulfilled, then a revelation mechanism based on direct and truthful communication may no longer be optimal. Indeed, with imperfect commitment the optimal mechanism may use some form of noisy communication that induces only partial information revelation (see Bester and Strausz (2001, 2003)).

In what follows, however, we sidestep the complications of noisy communication. Instead, we focus on the question of whether a direct and truthful mechanism can implement the same allocation of decision rights as under perfect information. A mechanism with this property is automatically efficient in special cases, where a first-best outcome can be achieved or contractual incompleteness does not invalidate the standard Revelation Principle. Conversely, if the Revelation Principle is applicable but the outcome under perfect information is not implementable through direct and truthful communication, then this yields the insight that asymmetric information necessarily reduces the ex ante available joint surplus. But also in cases where the standard Revelation Principle fails, the implementability of the perfect information outcome provides an important insight: It shows that the presence of asymmetric information cannot reduce the organization's surplus. Potentially, it may even increase it. Indeed, while imperfect information can only be harmful with complete contracts, it is well-known that it may enhance efficiency in an incomplete contracting environment because it can serve as a partial commitment device.

\footnotetext{
${ }^{8}$ In an incomplete information framework, Aghion, Dewatripont and Rey (2004) show that the transfer of control rights can be used to allow the other party to establish a reputation for future cooperation. See also Aghion and Bolton (1992) who demonstrate in a model of debt financing that it may be optimal to transfer control in certain states of the world.

${ }^{9}$ See Gibbard (1973), Green and Laffont (1977), Dasgupta et. al. (1979) and Myerson (1979)
} 
In this section, we assume that each agent is privately informed about his type. Agent 1's type is denoted as $t_{1} \in T_{1}=\left\{t_{11}, \ldots, t_{1 k}, \ldots, t_{1 m}\right\}$; agent 2's type is $t_{2} \in$ $T_{2}=\left\{t_{21}, \ldots, t_{2 \ell}, \ldots, t_{2 n}\right\}$. The agents' types are independently distributed according to the probability distributions $p_{1}\left(t_{1}\right)$ and $p_{2}\left(t_{2}\right)$, respectively. Given a decision $d \in D$ and a transfer $w$, the payoffs of the two agents depend on the realization $\left(t_{1}, t_{2}\right)$ according to

$$
u_{1}\left(d \mid t_{1}, t_{2}\right)-w, \quad u_{2}\left(d \mid t_{1}, t_{2}\right)+w
$$

The agents sign a contract ex ante before they observe their types. As indicated above, we focus on direct mechanisms that are Bayesian incentive compatible. Thus each agent $i$ reports some type $\tau_{i} \in T_{i}$ at the interim stage after having observed the realization of $t_{i}$. As a function of these reports, a contract specifies the allocation of authority and a transfer. Given the reports $\left(\tau_{1}, \tau_{2}\right)$ the decision right is assigned to agent 1 with probability $h\left(\tau_{1}, \tau_{2}\right)$ and to agent 2 with the remaining probability $1-h\left(\tau_{1}, \tau_{2}\right)$. Also, agent 1 has to transfer the amount $w\left(\tau_{1}, \tau_{2}\right)$ to agent 2 . In summary, in this section a contract is described by $\gamma=(h(\cdot), w(\cdot))$ with $h: T_{1} \times T_{2} \rightarrow$ $[0,1]$ and $w: T_{1} \times T_{2} \rightarrow \mathbb{R}$.

Suppose that each agent believes that the other agent reports his type truthfully. Then the agents' preferred decisions are

$$
d^{1}\left(t_{1}, \tau_{2}\right)=\operatorname{argmax}_{d \in D} u_{1}\left(d \mid t_{1}, \tau_{2}\right), \quad d^{2}\left(\tau_{1}, t_{2}\right)=\operatorname{argmax}_{d \in D} u_{2}\left(d \mid \tau_{1}, t_{2}\right) .
$$

For a given contract $\gamma$ define

$$
\begin{aligned}
U_{1}^{\gamma}\left(\tau_{1} \mid t_{1}\right) & \equiv \sum_{t_{2} \in T_{2}}\left[h\left(\tau_{1}, t_{2}\right) u_{1}\left(d^{1}\left(t_{1}, t_{2}\right) \mid t_{1}, t_{2}\right)\right. \\
& \left.+\left[1-h\left(\tau_{1}, t_{2}\right)\right] u_{1}\left(d^{2}\left(\tau_{1}, t_{2}\right) \mid t_{1}, t_{2}\right)-w\left(\tau_{1}, t_{2}\right)\right] p_{2}\left(t_{2}\right), \\
U_{2}^{\gamma}\left(\tau_{2} \mid t_{2}\right) & \equiv \sum_{t_{1} \in T_{1}}\left[h\left(t_{1}, \tau_{2}\right) u_{2}\left(d^{1}\left(t_{1}, \tau_{2}\right) \mid t_{1}, t_{2}\right)\right. \\
& \left.+\left[1-h\left(t_{1}, \tau_{2}\right)\right] u_{2}\left(d^{2}\left(t_{1}, t_{2}\right) \mid t_{1}, t_{2}\right)+w\left(t_{1}, \tau_{2}\right)\right] p_{1}\left(t_{1}\right) .
\end{aligned}
$$

Thus $U_{i}^{\gamma}\left(\tau_{i} \mid t_{i}\right)$ is agent $i$ 's expected payoff from announcing type $\tau_{i}$ when his actual type is $t_{i}$ and the other agent always announces his type truthfully. A contract $\gamma=(h(\cdot), w(\cdot))$ is Bayesian incentive compatible if truthful reporting is optimal for each agent, i.e. if

$$
U_{1}^{\gamma}\left(t_{1} \mid t_{1}\right) \geq U_{1}^{\gamma}\left(\tau_{1} \mid t_{1}\right), \quad U_{2}^{\gamma}\left(t_{2} \mid t_{2}\right) \geq U_{2}^{\gamma}\left(\tau_{2} \mid t_{2}\right)
$$

for all $t_{1}, \tau_{1} \in T_{1}$ and all $t_{2}, \tau_{2} \in T_{2}$. Under an incentive compatible contract the ex ante expected payoffs of the two agents are

$$
U_{i}(\gamma) \equiv \sum_{t_{i} \in T_{i}} U_{i}^{\gamma}\left(t_{i} \mid t_{i}\right) p_{i}\left(t_{i}\right), \quad i=1,2
$$


Note that if agent $i$ could directly observe the other agent's type, his valuation of authority, as defined in (5), would depend on $\left(t_{1}, t_{2}\right)$ according to

$$
v_{i}\left(t_{1}, t_{2}\right)=u_{i}\left(d^{i}\left(t_{1}, t_{2}\right) \mid t_{1}, t_{2}\right)-u_{i}\left(d^{j}\left(t_{1}, t_{2}\right) \mid t_{1}, t_{2}\right), \quad j \neq i .
$$

Thus, it follows from Proposition 1 that the efficient allocation of the decision right under perfect information is contingent upon the type realization $\left(t_{1}, t_{2}\right)$ and satisfies

$$
h^{*}\left(t_{1}, t_{2}\right) \in \operatorname{argmax}_{h \in[0,1]} h\left[v_{1}\left(t_{1}, t_{2}\right)-v_{2}\left(t_{1}, t_{2}\right)\right] .
$$

If an incentive compatible contract supports $h^{*}(\cdot, \cdot)$, then this contract yields the same surplus as under perfect information. Therefore, both agents may achieve the same ex ante payoffs as under perfect information ${ }^{10}$

In the following example of one-sided asymmetric information, a firm owner is better informed about the project's success probability than his manager. Under symmetric information it is efficient to undertake the project only if the likelihood of success is high. The same outcome is implementable under asymmetric information through an incentive compatible contract. In fact, since there are only two alternatives, Proposition 2 implies that this contract achieves the first-best.

EXAMPLE 3 A firm owner (agent 1) can undertake a project together with a manager (agent 2). Let $D=\left\{d_{Y}, d_{N}\right\}$. If $d=d_{N}$, the project is cancelled and both agents receive zero payoffs. If $d=d_{Y}$, the manager incurs the effort cost $e>0$. The project is successful with probability $t_{1} \in\left\{t_{L}, t_{H}\right\} \subset[0,1]$. In the event of success the firm owner receives the payoff $X>0$; otherwise his payoff is zero. Thus the agents' expected payoffs are

$$
u_{1}\left(d_{N} \mid t_{1}\right)=u_{2}\left(d_{N}\right)=0, \quad u_{1}\left(d_{Y} \mid t_{1}\right)=t_{1} X, \quad u_{2}\left(d_{Y}\right)=-e .
$$

Only the owner knows the probability of success $t_{1}$. Let $0<t_{L}<e / X<t_{H}<1$ so that it is efficient to select $d=d_{Y}$ only if $t_{1}=t_{H}$.

Since $u_{1}\left(d_{Y} \mid t_{1}\right)>u_{1}\left(d_{N} \mid t_{1}\right)$ and $u_{2}\left(d_{N}\right)>u_{2}\left(d_{Y}\right)$, we have $d^{1}\left(t_{L}\right)=d^{1}\left(t_{H}\right)=d_{Y}$ and $d^{2}=d_{N}$. Therefore, an efficient contract under perfect information sets $h^{*}\left(t_{H}\right)=$ 1 and $h^{*}\left(t_{L}\right)=0$. The same allocation of authority can be implemented under asymmetric information because the firm owner's incentive compatibility restrictions

$$
t_{H} X-w\left(t_{H}\right) \geq-w\left(t_{L}\right), \quad-w\left(t_{L}\right) \geq t_{L} X-w\left(t_{H}\right)
$$

are satisfied for any $w(\cdot)$ such that $t_{L} X \leq w\left(t_{H}\right)-w\left(t_{L}\right) \leq t_{H} X$.

\footnotetext{
${ }^{10}$ Indeed, if $\gamma=(h(\cdot), w(\cdot))$ is incentive compatible, then for any $\alpha \in \mathbb{R}$ also $\gamma^{\prime}=(h(\cdot), w(\cdot)+\alpha)$ is incentive compatible.
} 
In Example 3 each agent's preference is independent of his partner's type. It thus satisfies the following condition:

Condition A For all $t_{1} \in T_{1}$ and all $t_{2}, t_{2}^{\prime} \in T_{2}, u_{1}\left(d \mid t_{1}, t_{2}\right)=u_{1}\left(d \mid t_{1}, t_{2}^{\prime}\right)$. Analogously, for all $t_{2} \in T_{2}$ and all $t_{1}, t_{1}^{\prime} \in T_{1}, u_{2}\left(d \mid t_{1}, t_{2}\right)=u_{2}\left(d \mid t_{1}^{\prime}, t_{2}\right)$.

This condition has the important implication that the standard Revelation Principle remains valid. Indeed, this principle may fail with imperfect commitment only because agent $i$ will refrain from revealing his type $t_{i}$ truthfully when his partner $j$ can exploit this information for taking a decision $d^{j}$ that depends on $t_{i}$ in a disadvantageous way for agent $i$. This cannot happen under Condition A because each agent's decision behavior is independent of his partner's type.

The externalities associated with authority suggest that one may use 'externality payments' as in the Clarke-Groves-Vickrey mechanism (see Clarke (1971), Groves (1973), Vickrey (1961)) to implement an efficient allocation of decision rights under imperfect information. Yet, it follows from (17) that each agent's valuation of authority depends not only on his own but also on the other agent's information. With such 'interdependent valuations' it is well-known (see e.g. Bergemann and Välimäki (2002), Dasgupta and Maskin (2000), Jehiel and Moldovanu (2001)) that efficient design may be impossible. Condition A does not rule out such interdependencies because agent $i$ 's valuation of authority stills depend on his partner's type $t_{j}$ if $d^{j}$ is affected by $t_{j}$. In Example 3 this is not the case because the individual's ranking of decisions does not depend on his private information. This property is made more precise by the following condition:

Condition B For all $d, d^{\prime} \in D$ and all $t_{1}, t_{1}^{\prime} \in T_{1}, u_{1}\left(d \mid t_{1}, t_{2}\right) \geq u_{1}\left(d^{\prime} \mid t_{1}, t_{2}\right)$ implies $u_{1}\left(d \mid t_{1}^{\prime}, t_{2}\right) \geq u_{1}\left(d^{\prime} \mid t_{1}^{\prime}, t_{2}\right)$. Analogously, for all $d, d^{\prime} \in D$ and all $t_{2}, t_{2}^{\prime} \in T_{2}$, $u_{2}\left(d \mid t_{1}, t_{2}\right) \geq u_{2}\left(d^{\prime} \mid t_{1}, t_{2}\right)$ implies $u_{2}\left(d \mid t_{1}, t_{2}^{\prime}\right) \geq u_{2}\left(d^{\prime} \mid t_{1}, t_{2}^{\prime}\right)$.

Condition $\mathrm{B}$ rules out that agent $i$ 's preference over $d$ and $d^{\prime}$ is reversed when he learns $t_{i}^{\prime}$ rather than $t_{i}$. It is easy to see that under Conditions $\mathrm{A}$ and $\mathrm{B}$, agent $i$ 's valuation of authority in (17) depends only on his own type and can be written as $v_{i}\left(t_{i}\right)$. This allows us to establish the following result by adopting an argument from d'Aspremont and Gerard-Varet (1979):

Proposition 5 Let $u_{1}(\cdot)$ and $u_{2}(\cdot)$ satisfy conditions $A$ and $B$. Then there exists an incentive compatible contract $\gamma=\left(h^{*}(\cdot), w(\cdot)\right)$ such that for all $\left(t_{1}, t_{2}\right) \in T_{1} \times T_{2}$ the allocation of the decision right is efficient under perfect information, i.e. $h^{*}(\cdot)$ satisfies (18).

Under the conditions of Proposition 5 it is indeed efficient to implement the same allocation of authority as under perfect information. This is so because by 
Condition A the Revelation Principle holds. Therefore, the efficient contract maximizes the agents' joint surplus subject to the incentive compatibility constraints in (15). Proposition 5 effectively shows that despite these constraints there is no loss of surplus and so the agents can obtain the same payoffs as under perfect information.

The following example satisfies Condition A, but not Condition B. It shows that Condition B is not dispensable in Proposition 5 because the perfect information allocation cannot be supported by an incentive compatible contract under certain parameter constellations. In this situation, the Revelation Principle implies that asymmetric information generates a welfare loss.

EXAmple 4 Agent 1's set of possible types is $T_{1}=\left\{t_{L}, t_{H}\right\} \subseteq \mathbb{R}_{+}$with $0<t_{L}<$ $1<t_{H}$. There is no uncertainty about agent 2's type. Depending on $t_{1} \in T_{1}$, the agent's payoffs are

$$
u_{1}\left(d \mid t_{1}\right)=d-0.5 t_{1} d^{2}, \quad u_{2}(d)=a d-0.5 d^{2},
$$

so that $d^{1}\left(t_{L}\right)=1 / t_{L}, d^{1}\left(t_{H}\right)=1 / t_{H}$ and $d^{2}=a$. By Proposition 3 , the optimal contract under perfect information about agent 1's type satisfies $h\left(t_{L}\right)=0, h\left(t_{H}\right)=$ 1. Implementing the same allocation of authority under asymmetric information requires that the following incentive constraints for type $t_{L}$ and $t_{H}$, respectively, are satisfied:

$$
\begin{aligned}
u_{1}\left(a \mid t_{L}\right)-w\left(t_{L}\right) & \geq u_{1}\left(1 / t_{L} \mid t_{L}\right)-w\left(t_{H}\right), \\
u_{1}\left(1 / t_{H} \mid t_{H}\right)-w\left(t_{H}\right) & \geq u_{1}\left(a \mid t_{H}\right)-w\left(t_{L}\right) .
\end{aligned}
$$

These inequalities have a solution for $w\left(t_{L}\right)$ and $w\left(t_{H}\right)$ if and only if

$$
u_{1}\left(1 / t_{H} \mid t_{H}\right)-u_{1}\left(a \mid t_{H}\right) \geq u_{1}\left(1 / t_{L} \mid t_{L}\right)-u_{1}\left(a \mid t_{L}\right) .
$$

By (21) this condition is equivalent to $\left(t_{H}-t_{L}\right)\left(a^{2} t_{H} t_{L}-1\right) /\left(2 t_{H} t_{L}\right) \geq 0$. Thus $h\left(t_{L}\right)=0$ and $h\left(t_{H}\right)=1$ is implementable if and only if $a \geq 1 / \sqrt{t_{H} t_{L}}$.

Example 4 illustrates the limitations of efficient design when agent $i$ 's decision behavior depends on his own information. Interestingly, however, the perfect information outcome is always implementable when each agent's payoff depends exclusively on the other agent's information. This is the case under the following condition:

Condition C: For each $\left(t_{1}, t_{2}\right) \in T_{1} \times T_{2}, u_{1}\left(d \mid t_{1}, t_{2}\right)=u_{1}\left(d \mid t_{1}^{\prime}, t_{2}\right)$ for all $t_{1}^{\prime} \in T_{1}$, and $u_{2}\left(d \mid t_{1}, t_{2}\right)=u_{2}\left(d \mid t_{1}, t_{2}^{\prime}\right)$ for all $t_{2}^{\prime} \in T_{2}$.

This condition describes situations in which the decision maker relies on the advice of the other party. As an application, suppose that in Example 3 the manager's 
type instead of the firm owner's type reflects the probability of success. With this modification of the example, the manager has private information about the project's likelihood of success, which determines the owner's expected payoff. The following Proposition shows that in such situations truthful information transmission can be achieved without loss of efficiency.

Proposition 6 Let $u_{1}(\cdot)$ and $u_{2}(\cdot)$ satisfy condition $C$. Then there exists an incentive compatible contract $\gamma=\left(h^{*}(\cdot), w(\cdot)\right)$ such that for all $\left(t_{1}, t_{2}\right) \in T_{1} \times T_{2}$ the allocation of the decision right is efficient under perfect information, i.e. $h^{*}(\cdot)$ satisfies (18).

Propositions 2 and 6 imply that the efficient contract under asymmetric information realizes the first-best surplus if Condition $\mathrm{C}$ holds and the set $D$ contains two elements. With more than two alternatives, however, it is not necessarily optimal to implement the same allocation of authority as under perfect information. This is so because Condition $\mathrm{C}$ does not allow us to appeal to the standard Revelation Principle. Therefore, direct and truthful communication may not be optimal. Nonetheless, we are able to conclude from Proposition 6 that an efficient contract achieves at least the same expected surplus as under perfect information. Asymmetric information can only be beneficial under Condition $\mathrm{C}$.

Example 4 shows that the perfect information allocation of authority may not be implementable under asymmetric information when agent $i$ 's decision behavior depends not only on his partner's but also on his own type. Yet, this does not rule out that this is possible in special cases. Indeed, one such special case is the environment described in (10), where agent $i$ 's ideal decision is $\theta_{i}$. Suppose now that $T_{1} \times T_{2} \subset \mathbb{R}_{+} \times \mathbb{R}_{+}$and that the agents' ideal decisions depend on their types according to

$$
\theta_{1}\left(t_{1}, t_{2}\right)=\beta t_{1}+(1-\beta) t_{2}, \quad \theta_{2}\left(t_{1}, t_{2}\right)=\beta t_{1}+(1-\beta) t_{2}+b,
$$

where $\beta \in[0,1]$ and $b>0$. Thus, agent 1's ideal decision is a weighted average of his and the other agent's information. The parameter $b=\theta_{2}-\theta_{1}$ represents the bias of agent 2 .

For $\beta=0$ the specification in (24) corresponds to the special case of one-sided asymmetric information, which is studied in Crawford and Sobel (1982), Dessein (2002), Krähmer (2004), and Krishna and Morgan (2004).11 Indeed, the following

\footnotetext{
${ }^{11}$ There are some further differences between our model and these authors: Crawford and Sobel (1982) and Dessein (2002) consider pure cheap-talk without transfers. In Crawford and Sobel (1982) and in Krishna and Morgan (2004) the uninformed agent is exogenously endowed with the decision authority. In Dessein (2002) the allocation of authority is independent of the information revealed at the interim stage.
} 
result generalizes a finding by Krishna and Morgan (2004) to the case of two-sided asymmetric information:

Proposition 7 Let $u_{1}(\cdot)$ and $u_{2}(\cdot)$ satisfy $(10)$ and $(24)$. Then there exists an incentive compatible contract $\gamma=\left(h^{*}(\cdot), w(\cdot)\right)$ such that for all $\left(t_{1}, t_{2}\right) \in T_{1} \times T_{2}$ the allocation of the decision right is efficient under perfect information, i.e. $h^{*}(\cdot)$ satisfies (18).

The proposition reveals that imperfect information generates no loss of surplus if the agents' preferences satisfy $(10)$ and (24). Potentially, it may be even welfare enhancing. In fact, for the case where $\beta=0$ and $h=1$ is exogenously fixed, Krishna and Morgan (2004) show that the optimal contract may entail partial rather than full information revelation by agent $2 \sqrt{12}$

\section{Multiple Decisions}

In reality, most organizations face a vast number of decision problems rather than a single problem. Also, typically it is not a single party that is in charge of all decisions. Instead decision rights are often decentralized and control rights in different areas are divided between different parties. As an example, a firm may have to decide which technology it uses for production. In addition, decisions on financing and marketing have to be made. It is not necessary and may not be desirable that the same party has authority over production, financing and marketing decisions.

To address the question of whether authority should be centralized or decentralized, we now consider a situation where the joint project requires $n$ separate noncontractible decisions $d_{k}, k=1, \ldots, n$. Decision $d_{k}$ has to be selected from the set $D_{k}$ of feasible alternatives. Let $D=D_{1} \times \ldots D_{k} \times \ldots D_{n}$ and $d=\left(d_{1}, \ldots, d_{k}, \ldots, d_{n}\right) \in D$. The agents' payoffs then depend on $d$ and the transfer $w$ as described by (1) and the joint surplus $S(d)$ from their decisions is given by (2).

A contract $\gamma=(h, w)$ specifies the transfer payment $w$ and the allocation of authority $h=\left(h_{1}, \ldots, h_{k}, \ldots, h_{n}\right)$ over the $n$ decision areas, where the variable $h_{k} \in$ $\{1,2\}$ indicates which agent has the discretion to select $d_{k} \in D_{k}$. Let $H$ denote the set of the $2^{n}$ feasible arrangements of $h$. Then, for a given contract $\gamma=(h, w)$, agent $i$ has control over all decisions in

$$
D^{i}(h) \equiv\left\{D_{k} \mid h_{k}=i\right\}
$$

\footnotetext{
${ }^{12}$ Krishna and Morgan (2004) consider a continuum of types. In a model with two types, Krähmer (2004) employs a generalized version of the Revelation Principle as developed by Bester and Strausz (2001) and shows that full separation is optimal.
} 
Note that, for all $h \in H, D^{1}(h) \cup D^{2}(h)=\cup_{k=1}^{n} D_{k}$. With slight abuse of notation we may write $d=\left(d^{1}, d^{2}\right) \in D$ for all $\left(d^{1}, d^{2}\right) \in D^{1} \times D^{2}$.

We first consider situations where the agents take their decisions simultaneously. Thus a contract implements the decisions $d=\left(d^{1}, d^{2}\right)$ if the agents' choices constitute a Nash-equilibrium, 13

$$
d^{1} \in \operatorname{argmax}_{d^{\prime} \in D^{1}(h)} u_{1}\left(d^{\prime}, d^{2}\right), \quad d^{2} \in \operatorname{argmax}_{d^{\prime} \in D^{2}(h)} u_{2}\left(d^{1}, d^{\prime}\right) .
$$

The following example shows that an inefficient allocation of authority may lead to an organizational Prisoner's Dilemma. This can be avoided by rearranging decision rights in such a way that 'cooperative' behavior is induced.

ExAmple 5 Let $n=2$ with $D_{1}=\{A, B\}$ and $D_{2}=\{X, Y\}$. The following table describes the agents' payoffs as the bi-matrix game that results from a contract with $h_{1}=1, h_{2}=2$ and the transfer $w \longdiv { 1 4 }$

\begin{tabular}{|c|c|c|}
\hline & $X$ & $Y$ \\
\hline$A$ & $5-w, 5+w$ & $0-w, 6+w$ \\
\hline$B$ & $6-w, 0+w$ & $1-w, 1+w$ \\
\hline
\end{tabular}

Thus when agent 1 selects $d_{1} \in\{A, B\}$ and agent 2 selects $d_{2} \in\{X, Y\}$, they are involved in a Prisoner's Dilemma. In the equilibrium $(B, Y)$ of the decision game they share the surplus $u_{1}(B, Y)+u_{2}(B, Y)=2$. It is easy to see, however, that the authority arrangement $h=(1,2)$ is inefficient. Indeed, a contract with $h=(2,1)$ results in the following game, in which agent 1 chooses between $X$ and $Y$ and agent 2 between $A$ and $B$ :

\begin{tabular}{|c|c|c|}
\hline & $A$ & $B$ \\
\hline$X$ & $5-w, 5+w$ & $6-w, 0+w$ \\
\hline$Y$ & $0-w, 6+w$ & $1-w, 1+w$ \\
\hline
\end{tabular}

This allocation of decision rights induces the Nash equilibrium $(A, X)$ and the transfer $w$ enables the two parties to share a surplus of 10 . Actually, $d=(A, X)$ is the (unique) first-best decision and so a contract is efficient if and only if $h=(2,1)$. $\diamond$

In Example 5 each of the agents' has a dominant decision strategy for any $h \in H$. That is, his most preferred alternative in $D_{k}$ is independent of the alternatives

\footnotetext{
${ }^{13}$ Note that 26 includes the case where one of the agents controls all decisions in $D$.

${ }^{14}$ In what follows, agent 1 is always identified as the row-player and agent 2 is identified as the column-player. In each cell, the first entry represents agent 1's and the second entry agent 2's payoff.
} 
selected in $D \backslash D_{k}$. More formally, let $\left(d_{k}^{\prime} ; d_{-k}\right)=\left(d_{1}, \ldots, d_{k-1}, d_{k}^{\prime}, d_{k+1}, \ldots, d_{n}\right)$. Then the agents' preferences in Example 5 satisfy the following condition:

Condition D: For $i=1,2$, and $k=1, \ldots, n$ there exists a $\hat{d}_{k}^{i} \in D_{k}$ such that for all $d_{k}^{\prime} \in D_{k} \backslash\left\{\hat{d}_{k}^{i}\right\}$

$$
u_{i}\left(\hat{d}_{k}^{i} ; d_{-k}\right)>u_{i}\left(d_{k}^{\prime} ; d_{-k}\right) \text { for all } d_{-k} .
$$

In addition to satisfying condition D, Example 5 has the property that each decision set $D_{k}$ contains two alternatives. These two properties are sufficient to support the first-best outcome as defined in (7).

Proposition 8 Suppose that condition D holds and that each $D_{k}$ consists of two alternatives. Then there exists a contract $\gamma=(h, w)$ such that $h$ implements the first-best decisions, i.e. $S\left(d^{1}, d^{2}\right)=S\left(d^{*}\right)$.

Proposition 8 generalizes Proposition 2 to the case of multiple simultaneous decisions. Condition D is important for this result because it ensures that for any arrangement of authority there is a (pure) strategy Nash-equilibrium in the agents' decision game so that $\left(d^{1}, d^{2}\right)$ in 26 is well-defined ${ }^{15}$ Indeed, the following example shows that the conclusion of Proposition 8 fails if condition D is violated.

ExAmple 6 Let $n=2$ with $D_{1}=\{A, B\}$ and $D_{2}=\{X, Y\}$. The agents' payoffs are

$$
\begin{gathered}
u_{1}(A, X)=5, u_{1}(A, Y)=0, u_{1}(B, X)=0, u_{1}(B, Y)=4 \\
u_{2}(A, X)=0, u_{2}(A, Y)=4, u_{2}(B, X)=3, u_{2}(B, Y)=2 .
\end{gathered}
$$

The first-best surplus is $S(B, Y)=6$. But $(B, Y)$ cannot be implemented through decentralized authority: If $\left(h_{1}, h_{2}\right)=(1,2)$ agent 2 will deviate because $u_{2}(B, X)=$ $3>u_{2}(B, Y)=2$; if $\left(h_{1}, h_{2}\right)=(2,1)$ agent 2 will deviate because $u_{2}(A, Y)=4>$ $u_{2}(B, Y)=2$. Neither can $(B, Y)$ be implemented through centralized authority: If $\left(h_{1}, h_{2}\right)=(1,1)$ agent 1 selects $(A, X)$; if $\left(h_{1}, h_{2}\right)=(2,2)$ agent 2 selects $(A, Y)$.

Actually, condition D is required for the generalization of Proposition 2 only if the agents take their decisions simultaneously and hence under imperfect information about their partners' choice. In a sequential decision process with perfect information about previous decisions, it is sufficient for implementation of the firstbest that each stage of the process consists of a binary choice problem. To show this, consider the following variation of the multiple decision environment: There

\footnotetext{
${ }^{15}$ We focus on pure strategy equilibria because the outcome of a mixed equilibrium typically does not satisfy $(7)$.
} 
are $n$ sequential stages, $k=1, \ldots, n$. In stage $k$, agent $i$ has the authority to select one of the alternatives $d_{k} \in D_{k}$ if the contract $\gamma=(h, w)$ specifies that $h_{k}=i$. Even though decisions are not verifiable to outsiders, we assume that the decision maker in stage $k$ is informed about the $k-1$ previous decisions ${ }^{16}$ The game ends with the payoffs described in (1) after the last decision $k=n$ has been made.

The multistage decision process has a subgame-perfect equilibrium for any arrangement $h$ of authority as long as each of the decision sets $D_{k}, k=1, \ldots, n$, is finite. ${ }^{17}$ This equilibrium implements the decisions $d=\left(d_{1}, \ldots, d_{k}, \ldots, d_{n}\right) \in D$ if on the equilibrium path decision $d_{k}$ is selected in stage $k$. By an induction argument on the number of stages we obtain the following generalization of Proposition 2 ;

Proposition 9 Suppose that decisions are taken sequentially under perfect information and that each $D_{k}$ consists of two alternatives. Then there exists a contract $\gamma=(h, w)$ such that the first-best decisions $d^{*}$ are implemented in a subgame-perfect equilibrium.

Propositions 8 and 9 indicate that it may be advantageous to split the overall decision process into several sub-decisions. Defining different areas of control allows the organization to fine-tune the allocation of decision rights and may enhance the efficiency of project selection. Indeed, decentralized control rights limit the excessive power of either party and may facilitate the implementation of a compromise between extreme positions. This point is illustrated in the following example ${ }^{18}$

EXAmple 7 Consider the set of alternatives $D=\left\{d_{0}, d_{L}, d_{H}\right\}$, where $d_{0}$ is interpreted as maintaining the status quo, while $d_{L}$ indicates a 'minor' and $d_{H}$ a 'major' restructuring of the organization. The agents have conflicting interests as

$$
\begin{aligned}
& u_{1}\left(d_{0}\right)=1, u_{1}\left(d_{L}\right)=3, u_{1}\left(d_{H}\right)=4, \\
& u_{2}\left(d_{0}\right)=4, u_{2}\left(d_{L}\right)=3, u_{2}\left(d_{H}\right)=1 .
\end{aligned}
$$

The first-best $d^{*}=d_{L}$ is not implementable by giving one of the agents' control over $D$ because $d^{1}=d_{H}$ and $d^{2}=d_{0}$.

But $d^{*}=d_{L}$ can be implemented by splitting $D$ into two decision stages: Let the feasible set $D_{1}=\left\{d_{0}, d_{R}\right\}$ in stage 1 contain two possible decisions. If $d_{0}$

\footnotetext{
${ }^{16}$ In principle, this would allow the use of some elicitation scheme which makes the contract contingent on the announcement of observations. Yet, this cannot increase welfare under the conditions of Proposition 9 because even without such a scheme the first-best is achievable.

${ }^{17}$ Indeed, every finite extensive game of perfect information has a subgame-perfect equilibrium; see e.g. Myerson (1991), Theorem 4.7, p. 186.

${ }^{18}$ The idea of the example corresponds to Tirole's (1999, p. 31) observation that it may be optimal to "circumscribe the action set available to the controlling stakeholder by ruling out those actions that are that are more likely to involve strong externalities on other stakeholders."
} 


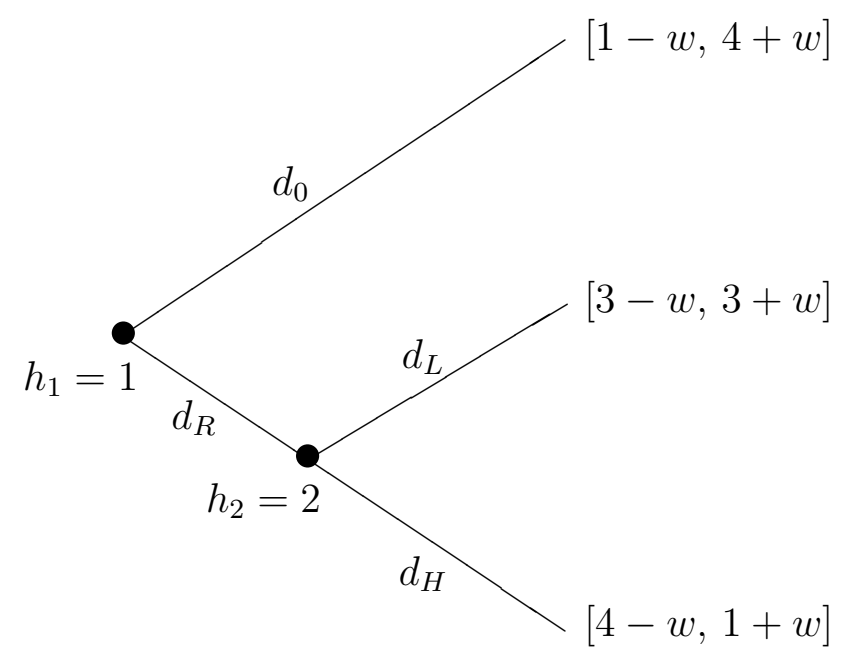

Figure 1: Multistage Decisions

is selected, the decision process ends and $d_{0}$ is implemented. If, however, $d_{R}$ is chosen in stage 1 , then in the second stage the feasible alternatives are $d_{L}$ and $d_{H}$, i.e. $D_{2}=\left\{d_{L}, d_{H}\right\}$. Figure 1 illustrates the game game tree with the sequence of decisions and the resulting payoffs. By backward induction it is easily verified that subgame perfection implements $d^{*}=d_{L}$ if $h_{1}=1$ and $h_{2}=2$.

In Examples 5 and 7 decentralized control rights are efficient so that each agent has authority over some aspect of the joint project. Of course, this is not necessarily so. Complementarity effects between different decisions may favor a centralized governance structure. To analyze how such effects affect the allocation of authority, we extend the payoffs in $(10)$ to an environment with $n=2$ decisions. Let $D=$ $D_{1} \times D_{2}=\mathbb{R}_{+}^{2}$ and

$$
u_{i}\left(d_{1}, d_{2}\right)=\bar{u}_{i}-k_{i} \ell\left(\left|\theta_{i 1}-d_{1}\right|,\left|\theta_{i 2}-d_{2}\right|\right),
$$

with $k_{i}>0.19$ The loss function $\ell: \mathbb{R}_{+}^{2} \rightarrow \mathbb{R}_{+}$is assumed to be strictly concave and to satisfy $\ell(0,0)=0, \partial \ell(x, y) / \partial x>0$ and $\partial \ell(x, y) / \partial y>0$. We assume that the agents have conflicting interest so that $\left|\theta_{1 k}-\theta_{2 k}\right|>0$ for $k=1,2$. The decisions $d_{1}$ and $d_{2}$ are complements if

$$
-\frac{\partial^{2} \ell(x, y)}{\partial x \partial y}>0
$$

If the inequality in (31) is reversed, the decisions are substitutes. The first part of the following result resembles the observation of Hart and Moore (1990) that

\footnotetext{
${ }^{19}$ Note that the payoffs in $\sqrt{30}$ satisfy condition D. Therefore, for given decision rights, simultaneous and sequential decisions lead to the same outcome.
} 
complementary assets should be owned together in the property rights theory of the firm.

Proposition 10 Suppose that $u_{1}(\cdot)$ and $u_{2}(\cdot)$ satisfy $(30)$. If the decisions $\left(d_{1}, d_{2}\right)$ are complements, then centralized decision rights with are efficient, and so $k_{i}>$ $k_{j}$ implies $h_{1}=h_{2}=i$ under an efficient contract. If the decisions $\left(d_{1}, d_{2}\right)$ are substitutes and $\left|k_{1}-k_{2}\right|$ is sufficiently small, then decentralized decision rights are efficient, i.e. $h_{1} \neq h_{2}$ under an optimal contract.

When decisions are complements, having authority over $D_{1}$ raises the valuation of obtaining control also over $D_{2}$. Therefore, decision rights should be centralized and, in line with Proposition 4, it is the agent with a higher weight $k_{i}$ who should select both $d_{1}$ and $d_{2}$. Analogously, decisions that are substitutes tend to favor decentralized control rights. Yet this tendency may be dominated by the the insight from Proposition 4 that agent $i$ 's valuation of authority increases with $k_{i}$. Therefore, substitutes lead to decentralized authority only if the difference between the weights $k_{1}$ and $k_{2}$ is not too large.

\section{Conclusions}

In a world of incomplete contracts, monetary incentives cannot fully reflect the impact of decisions on the benefits and costs of all members of the organization. The party who has authority over decisions will typically fail to take these externalities into account and so its objective will differ from maximizing the overall surplus. When the interests of the organization's stakeholders diverge, the surplus that can be realized depends on the identity of the decision maker. The optimal allocation of authority assigns the decision right to the party whose objective is most closely aligned with maximizing the joint surplus.

Our approach to the allocation of authority can easily integrate other factors that play a role in the design of organizations. For example, we have discussed the role asymmetric information and the interaction between multiple decision areas. A potentially interesting extension of our model is to consider a multi-person organization facing a number of decision problems. This would allow studying more complex forms of authority relationships. Also, it may be worth noting that our approach is applicable not only to firms but also to other institutions. For example, it might be used to analyse the distribution of authority between different governmental institutions. 


\section{Appendix}

Proof of Proposition 1: We first show that if the contract $\gamma=(1, w)$ is efficient, then $v_{1} \geq v_{2}$. Suppose the contrary, i.e. that $\gamma=(1, w)$ is efficient but $v_{2}>v_{1}$. Consider the contract $\gamma^{\prime}=\left(2, w^{\prime}\right)$ with

$$
w^{\prime} \equiv w+\left[u_{1}\left(d^{2}\right)-u_{1}\left(d^{1}\right)\right] / 2-\left[u_{2}\left(d^{2}\right)-u_{2}\left(d^{1}\right)\right] / 2 .
$$

Then $U_{1}\left(\gamma^{\prime}\right)=u_{1}\left(d^{2}\right)-w^{\prime}$ so that

$$
\begin{aligned}
U_{1}\left(\gamma^{\prime}\right) & =\left[u_{1}\left(d^{2}\right)+u_{1}\left(d^{1}\right)\right] / 2+\left[u_{2}\left(d^{2}\right)-u_{2}\left(d^{1}\right)\right] / 2-w \\
& =u_{1}\left(d^{1}\right)-w+\left[u_{1}\left(d^{2}\right)-u_{1}\left(d^{1}\right)\right] / 2+\left[u_{2}\left(d^{2}\right)-u_{2}\left(d^{1}\right)\right] / 2 \\
& =U_{1}(\gamma)+\left[v_{2}-v_{1}\right] / 2 .
\end{aligned}
$$

Similarly, $U_{2}\left(\gamma^{\prime}\right)=u_{2}\left(d^{2}\right)+w^{\prime}$ so that

$$
\begin{aligned}
U_{2}\left(\gamma^{\prime}\right) & =\left[u_{1}\left(d^{2}\right)-u_{1}\left(d^{1}\right)\right] / 2+\left[u_{2}\left(d^{2}\right)+u_{2}\left(d^{1}\right)\right] / 2+w \\
& =u_{2}\left(d^{1}\right)+w+\left[u_{1}\left(d^{2}\right)-u_{1}\left(d^{1}\right)\right] / 2+\left[u_{2}\left(d^{2}\right)-u_{2}\left(d^{1}\right)\right] / 2 \\
& =U_{2}(\gamma)+\left[v_{2}-v_{1}\right] / 2 .
\end{aligned}
$$

Since $v_{2}>v_{1}, U_{1}\left(\gamma^{\prime}\right)>U_{1}(\gamma)$ and $U_{2}\left(\gamma^{\prime}\right)>U_{2}(\gamma)$. Thus, the contract $\gamma$ is not efficient, a contradiction. An analogous argument proves that efficiency of $\gamma=(2, w)$ implies $v_{2} \geq v_{1}$.

We next show that $v_{1} \geq v_{2}$ implies that $\gamma=(1, w)$ is efficient. Suppose the contrary, i.e. that $v_{1} \geq v_{2}$ and $\gamma=(1, w)$ is not efficient. Then there is a contract $\gamma^{\prime}=\left(h, w^{o}\right)$ such that

$$
u_{1}\left(d^{h}\right)-w^{o} \geq u_{1}\left(d^{1}\right)-w, \quad u_{2}\left(d^{h}\right)+w^{o} \geq u_{2}\left(d^{1}\right)+w
$$

with at least one inequality holding strictly. Adding the two inequalities therefore yields

$$
u_{2}\left(d^{h}\right)-u_{2}\left(d^{1}\right)>u_{1}\left(d^{1}\right)-u_{1}\left(d^{h}\right),
$$

which implies $h=2$. Thus (36) is equivalent to $v_{2}>v_{1}$, a contradiction. An analogous argument proves that efficiency $v_{2} \geq v_{1}$ implies that $\gamma=(2, w)$ is efficient.

The second statement of Proposition 1 follows simply from the observation that, by (2) and (5), $S\left(d^{i}\right) \geq S\left(d^{j}\right)$ is equivalent to $v_{i} \geq v_{j}$.

Q.E.D.

Proof of Proposition 2: We first show that $S\left(d^{*}\right)>S(d)$ implies that $u_{i}\left(d^{*}\right)>$ $u_{i}(d)$ for at least some $i \in\{1,2\}$. Suppose the contrary, i.e.

$$
u_{1}\left(d^{*}\right) \leq u_{1}(d) \quad \text { and } \quad u_{2}\left(d^{*}\right) \leq u_{2}(d)
$$


This implies

$$
u_{1}\left(d^{*}\right)+u_{2}\left(d^{*}\right) \leq u_{1}(d)+u_{2}(d),
$$

and so, by (2), $S\left(d^{*}\right) \leq S(d)$, a contradiction. Thus, if $D=\left\{d^{*}, d\right\}$ with $S\left(d^{*}\right)>$ $S(d)$, there is an $i \in\{1,2\}$ such that $d^{i}=d^{*}$.

Now suppose that $\gamma=(h, w)$ is efficient but $d^{h}=d \neq d^{*}=d^{i}$. Then $S\left(d^{h}\right)=$ $S(d)<S\left(d^{*}\right)=S\left(d^{i}\right)$, a contradiction to the second statement of Proposition 1 .

Conversely, suppose that $\gamma=(i, w)$ implements the first-best decision $d^{*}$ but that $\gamma$ is not efficient. Then there is an efficient contract $\gamma=\left(j, w^{\prime}\right)$ which implements the decision $d \neq d^{*}$. Thus, $d^{i}=d^{*}$ and $d^{j}=d$ and $S\left(d^{j}\right)=S(d)<S\left(d^{*}\right)=S\left(d^{i}\right)$. By the second statement of Proposition 1, this contradicts efficiency of $\gamma=\left(j, w^{\prime}\right)$.

Q.E.D.

Proof of Proposition 3: Without loss of generality, let $d^{1}<d^{2}$. Then for all $d>d^{1}$,

$$
\int_{d^{1}}^{d} u_{1}^{\prime \prime}(x) \mathrm{d} x=\left[u_{1}^{\prime}(x)\right]_{d^{1}}^{d}=u_{1}^{\prime}(d)-u_{1}^{\prime}\left(d^{1}\right)=u_{1}^{\prime}(d),
$$

because $d^{1}=\operatorname{argmax}_{d} u_{1}(d)$ implies $u_{1}^{\prime}\left(d^{1}\right)=0$. Analogously, for all $d<d_{2}$,

$$
\int_{d}^{d^{2}} u_{2}^{\prime \prime}(x) \mathrm{d} x=\left[u_{2}^{\prime}(x)\right]_{d}^{d^{2}}=u_{2}^{\prime}\left(d^{2}\right)-u_{2}^{\prime}(d)=-u_{2}^{\prime}(d)
$$

Moreover,

$$
u_{1}\left(d^{1}\right)-u_{1}\left(d^{2}\right)=\int_{d^{2}}^{d^{1}} u_{1}^{\prime}(d) \mathrm{d} d, \quad u_{2}\left(d^{2}\right)-u_{2}\left(d^{1}\right)=\int_{d^{1}}^{d^{2}} u_{2}^{\prime}(d) \mathrm{d} d,
$$

and so by (39) and (40)

$$
\begin{array}{r}
{\left[u_{1}\left(d^{1}\right)-u_{1}\left(d^{2}\right)\right]-\left[u_{2}\left(d^{2}\right)-u_{2}\left(d^{1}\right)\right]=-\int_{d^{1}}^{d^{2}}\left[u_{1}^{\prime}(d)+u_{2}^{\prime}(d)\right] \mathrm{d} d} \\
=-\int_{d^{1}}^{d^{2}}\left[\int_{d^{1}}^{d} u_{1}^{\prime \prime}(x) \mathrm{d} x-\int_{d}^{d^{2}} u_{2}^{\prime \prime}(x) \mathrm{d} x\right] \mathrm{d} d \geq \\
-\int_{d^{1}}^{d^{2}}\left[\int_{d^{1}}^{d} \max _{z} u_{1}^{\prime \prime}(z) \mathrm{d} x-\int_{d}^{d^{2}} \min _{z} u_{2}^{\prime \prime}(z) \mathrm{d} x\right] \mathrm{d} d .
\end{array}
$$

Now let $\min _{d}\left|u_{1}^{\prime \prime}(d)\right|=-\max _{z} u_{1}^{\prime \prime}(z)>\max _{d}\left|u_{2}^{\prime \prime}(d)\right|=-\min _{z} u_{2}^{\prime \prime}(z)$. Then 42 implies

$$
\begin{array}{r}
{\left[u_{1}\left(d^{1}\right)-u_{1}\left(d^{2}\right)\right]-\left[u_{2}\left(d^{2}\right)-u_{2}\left(d^{1}\right)\right]>} \\
-\int_{d^{1}}^{d^{2}}\left[\int_{d^{1}}^{d} \min _{z} u_{2}^{\prime \prime}(z) \mathrm{d} x-\int_{d}^{d^{2}} \min _{z} u_{2}^{\prime \prime}(z) \mathrm{d} x\right] \mathrm{d} d= \\
\int_{d^{1}}^{d^{2}} \min _{z} u_{2}^{\prime \prime}(z)\left[d^{1}+d^{2}-2 d\right] \mathrm{d} d=0 .
\end{array}
$$


By (5) this proves that $\min _{d}\left|u_{1}^{\prime \prime}(d)\right|>\max _{d}\left|u_{2}^{\prime \prime}(d)\right|$ implies $v_{1}>v_{2}$. An analogous argument for the case $\min _{d}\left|u_{2}^{\prime \prime}(d)\right|>\max _{d}\left|u_{1}^{\prime \prime}(d)\right|$ completes the proof. Q.E.D.

Proof of Proposition 4: By (5) and (10),

$$
v_{1}=k_{1}\left[\ell\left(\left|\theta_{1}-d^{2}\right|\right)-\ell\left(\left|\theta_{1}-d^{1}\right|\right)\right], \quad v_{2}=k_{2}\left[\ell\left(\left|\theta_{2}-d^{1}\right|\right)-\ell\left(\left|\theta_{2}-d^{2}\right|\right)\right] .
$$

By (3) and (10), we have $d^{1}=\theta_{1}$ and $d^{2}=\theta_{2}$. Therefore, (44) simplifies to

$$
v_{1}=k_{1} \ell\left(\left|\theta_{1}-\theta_{2}\right|\right), \quad v_{2}=k_{2} \ell\left(\left|\theta_{2}-\theta_{1}\right|\right) .
$$

Since $\left|\theta_{1}-\theta_{2}\right|=\left|\theta_{2}-\theta_{1}\right|>0$, this proves that $k_{i}>k_{j}$ implies $v_{i}>v_{j}$.

Q.E.D.

Proof of Proposition 5: By conditions A and B, $d^{i}\left(t_{1}, t_{2}\right)$ is independent of $\left(t_{1}, t_{2}\right)$ and may be written simply as $d^{i}$. Similarly, by condition A, $u_{1}\left(d \mid t_{1}, t_{2}\right)$ and $u_{2}\left(d \mid t_{1}, t_{2}\right)$ simplify to $u_{1}\left(d \mid t_{1}\right)$ and $u_{2}\left(d \mid t_{2}\right)$. Define

$$
\begin{aligned}
& \bar{w}_{1}\left(\tau_{2}\right) \equiv \sum_{t_{1} \in T_{1}}\left[h\left(t_{1}, \tau_{2}\right) u_{1}\left(d^{1} \mid t_{1}\right)+\left[1-h\left(t_{1}, \tau_{2}\right)\right] u_{1}\left(d^{2} \mid t_{1}\right)\right] p_{1}\left(t_{1}\right), \\
& \bar{w}_{2}\left(\tau_{1}\right) \equiv \sum_{t_{2} \in T_{2}}\left[h\left(\tau_{1}, t_{2}\right) u_{2}\left(d^{1} \mid t_{2}\right)+\left[1-h\left(\tau_{1}, t_{2}\right)\right] u_{2}\left(d^{2} \mid t_{2}\right)\right] p_{2}\left(t_{2}\right) .
\end{aligned}
$$

For all $\left(\tau_{1}, \tau_{2}\right) \in T_{1} \times T_{2}$ let

$$
w\left(\tau_{1}, \tau_{2}\right) \equiv \bar{w}_{1}\left(\tau_{2}\right)-\bar{w}_{2}\left(\tau_{1}\right)+\alpha .
$$

where $\alpha$ is an arbitrary real number.

Now consider a contract $\gamma=\left(h^{*}(\cdot), w(\cdot)\right)$ where $h^{*}(\cdot)$ satisfies (18) and $w(\cdot)$ is given by (47). Then for agent 1 of type $t_{1}$ the incentive compatibility condition is equivalent to

$$
\begin{array}{r}
\sum_{t_{2} \in T_{2}}\left[h^{*}\left(t_{1}, t_{2}\right)-h^{*}\left(\tau_{1}, t_{2}\right)\right]\left[u_{1}\left(d^{1} \mid t_{1}\right)-u_{1}\left(d^{2} \mid t_{1}\right)\right] p_{2}\left(t_{2}\right) \\
\geq \sum_{T_{2}}\left[w\left(t_{1}, t_{2}\right)-w\left(\tau_{1}, t_{2}\right)\right] p_{2}\left(t_{2}\right)
\end{array}
$$

for all $\tau_{1} \in T_{1}$.

By 46) and (47),

$$
\begin{aligned}
& \sum_{t_{2} \in T_{2}}\left[w\left(t_{1}, t_{2}\right)-w\left(\tau_{1}, t_{2}\right)\right] p_{2}\left(t_{2}\right)= \\
& \sum_{t_{2} \in T_{2}}\left[\bar{w}_{2}\left(\tau_{1}\right)-\bar{w}_{2}\left(t_{1}\right)\right] p_{2}\left(t_{2}\right)= \\
& -\sum_{t_{2} \in T_{2}}\left[h^{*}\left(t_{1}, t_{2}\right)-h^{*}\left(\tau_{1}, t_{2}\right)\right]\left[u_{2}\left(d^{1} \mid t_{2}\right)-u_{2}\left(d^{2} \mid t_{2}\right)\right] p_{2}\left(t_{2}\right) .
\end{aligned}
$$

Therefore, (48) is equivalent to

$$
\begin{aligned}
& \sum_{t_{2} \in T_{2}}\left[h^{*}\left(t_{1}, t_{2}\right)-h^{*}\left(\tau_{1}, t_{2}\right)\right] \sum_{i}\left[u_{i}\left(d^{1} \mid t_{i}\right)-u_{i}\left(d^{2} \mid t_{i}\right)\right] p_{2}\left(t_{2}\right)= \\
& \sum_{t_{2} \in T_{2}}\left[h^{*}\left(t_{1}, t_{2}\right)-h^{*}\left(\tau_{1}, t_{2}\right)\right]\left[v_{1}\left(t_{1}\right)-v_{2}\left(t_{2}\right)\right] p_{2}\left(t_{2}\right) \geq 0 .
\end{aligned}
$$


By (18), $h^{*}\left(t_{1}, t_{2}\right)\left[v_{1}\left(t_{1}\right)-v_{2}\left(t_{2}\right)\right] \geq h^{*}\left(\tau_{1}, t_{2}\right)\left[v_{1}\left(t_{1}\right)-v_{2}\left(t_{2}\right)\right]$ for all $\left(t_{1}, t_{2}\right) \in T_{1} \times T_{2}$ and all $\tau \in T_{1}$. Thus the inequality in (50) holds and the contract specified by (18) and (47) satisfies the incentive compatibility conditions for agent 1. An analogous argument for agent 2 completes the proof.

Q.E.D.

Proof of Proposition 6: By condition C, $u_{1}\left(d \mid t_{1}, t_{2}\right)$ and $u_{2}\left(d \mid t_{1}, t_{2}\right)$ simplify to $u_{1}\left(d \mid t_{2}\right)$ and $u_{2}\left(d \mid t_{1}\right)$, respectively. Similarly, $d^{1}\left(t_{1}, t_{2}\right)$ simplifies to $d^{1}\left(t_{2}\right)$ and $d^{2}\left(t_{1}, t_{2}\right)$ simplifies to $d^{2}\left(t_{1}\right)$. Define

$$
\begin{aligned}
& \bar{w}_{1}\left(\tau_{2}\right) \equiv \sum_{t_{1} \in T_{1}}\left[h\left(t_{1}, \tau_{2}\right) u_{2}\left(d^{1}\left(\tau_{2}\right) \mid t_{1}\right)+\left[1-h\left(t_{1}, \tau_{2}\right)\right] u_{2}\left(d^{2}\left(t_{1}\right) \mid t_{1}\right)\right] p_{1}\left(t_{1}\right),(51) \\
& \bar{w}_{2}\left(\tau_{1}\right) \equiv \sum_{t_{2} \in T_{2}}\left[h\left(\tau_{1}, t_{2}\right) u_{1}\left(d^{1}\left(t_{2}\right) \mid t_{2}\right)+\left[1-h\left(\tau_{1}, t_{2}\right)\right] u_{1}\left(d^{2}\left(\tau_{1}\right) \mid t_{2}\right)\right] p_{2}\left(t_{2}\right),
\end{aligned}
$$

and for all $\left(\tau_{1}, \tau_{2}\right) \in T_{1} \times T_{2}$ let

$$
w\left(\tau_{1}, \tau_{2}\right) \equiv \bar{w}_{2}\left(\tau_{1}\right)-\bar{w}_{1}\left(\tau_{2}\right)+\alpha,
$$

where $\alpha$ is an arbitrary real number.

Now consider a contract $\gamma=\left(h^{*}(\cdot), w(\cdot)\right)$ where $h^{*}(\cdot)$ satisfies (18) and $w(\cdot)$ is given by (52). Then for agent 1 of type $t_{1}$ the incentive compatibility condition is equivalent to

$$
\begin{aligned}
& \sum_{t_{2} \in T_{2}}\left[h^{*}\left(t_{1}, t_{2}\right) u_{1}\left(d^{1}\left(t_{2}\right) \mid t_{2}\right)+\left[1-h^{*}\left(t_{1}, t_{2}\right)\right] u_{1}\left(d^{2}\left(t_{1}\right) \mid t_{2}\right)\right] p_{2}\left(t_{2}\right)- \\
& \sum_{t_{2} \in T_{2}}\left[h^{*}\left(\tau_{1}, t_{2}\right) u_{1}\left(d^{1}\left(t_{2}\right) \mid t_{2}\right)+\left[1-h^{*}\left(\tau_{1}, t_{2}\right)\right] u_{1}\left(d^{2}\left(\tau_{1}\right) \mid t_{2}\right)\right] p_{2}\left(t_{2}\right) \geq \\
& \sum_{t_{2} \in T_{2}}\left[w\left(t_{1}, t_{2}\right)-w\left(\tau_{1}, t_{2}\right)\right] p_{2}\left(t_{2}\right)
\end{aligned}
$$

for all $\tau_{1} \in T_{1}$. By 52$)$ and because $\sum_{t_{2} \in T_{2}} p_{2}\left(t_{2}\right)=1$,

$$
\sum_{t_{2} \in T_{2}}\left[w\left(t_{1}, t_{2}\right)-w\left(\tau_{1}, t_{2}\right)\right] p_{2}\left(t_{2}\right)=\bar{w}_{2}\left(t_{1}\right)-\bar{w}_{2}\left(\tau_{1}\right) .
$$

From the definition of $\bar{w}_{2}(\cdot)$ in (51) it follows immediately that (53) holds. Thus $\gamma=\left(h^{*}(\cdot), w(\cdot)\right)$ satisfies the incentive compatibility conditions for agent 1 . An analogous argument for agent 2 completes the proof.

Q.E.D.

Proof of Proposition 7: By Proposition 4, under perfect information the efficient allocation of authority depends only on the parameters $\left(k_{1}, k_{2}\right)$ and not on the agents types. First consider the case $h^{*}=1$ which is efficient under perfect information as long as $k_{1} \geq k_{2}$. Since $h^{*}=1$, agent 1 will select a decision that depends on agent 2 's report $\tau_{2}$ so that $d^{1}=\theta_{1}\left(t_{1}, \tau_{2}\right)=\beta t_{1}+(1-\beta) \tau_{2}$ when incentive compatibility is satisfied. Therefore

$$
\begin{aligned}
& U_{1}^{\gamma}\left(\tau_{1} \mid t_{1}\right)=\sum_{t_{2} \in T_{2}}\left[\bar{u}_{1}-k_{1} \ell(0)-w\left(\tau_{1}, t_{2}\right)\right] p_{2}\left(t_{2}\right), \\
& U_{2}^{\gamma}\left(\tau_{2} \mid t_{2}\right)=\sum_{t_{1} \in T_{1}}\left[\bar{u}_{2}-k_{2} \ell\left(\left|(1-\beta)\left(t_{2}-\tau_{2}\right)+b\right|\right)+w\left(t_{1}, \tau_{2}\right)\right] p_{1}\left(t_{1}\right) .
\end{aligned}
$$


Let

$$
w\left(\tau_{1}, \tau_{2}\right) \equiv-(1-\beta) k_{2} \ell^{\prime}(b) \tau_{2}+\alpha,
$$

where $\alpha$ is an arbitrary real number. Then the incentive compatibility condition $U_{1}^{\gamma}\left(t_{1} \mid t_{1}\right) \geq U_{1}^{\gamma}\left(\tau_{1} \mid t_{1}\right)$ for agent 1 is satisfied because $w\left(\tau_{1}, \tau_{2}\right)$ does not depend on $\tau_{1}$.

We now show that the incentive compatibility condition $U_{2}^{\gamma}\left(t_{2} \mid t_{2}\right) \geq U_{2}^{\gamma}\left(\tau_{2} \mid t_{2}\right)$ for agent 2 is satisfied. Note that for all $\tau_{2}<t_{2}+b /(1-\beta)$

$$
\frac{\partial U_{2}^{\gamma}\left(\tau_{2} \mid t_{2}\right)}{\partial \tau_{2}}=(1-\beta) k_{2}\left[\ell^{\prime}\left(\left|(1-\beta)\left(t_{2}-\tau_{2}\right)+b\right|\right)-\ell^{\prime}(b)\right] .
$$

Thus for $\tau_{2}<t_{2}$ we have $\partial U_{2}^{\gamma}\left(\tau_{2} \mid t_{2}\right) / \partial \tau_{2} \geq 0$ because $\ell^{\prime \prime}(\cdot)>0$ and $\mid(1-\beta)\left(t_{2}-\right.$ $\left.\tau_{2}\right)+b \mid \geq b$. Similarly for $t_{2} \leq \tau_{2}<t_{2}+b /(1-\beta), \partial U_{2}^{\gamma}\left(\tau_{2} \mid t_{2}\right) / \partial \tau_{2} \leq 0$ because $\left|(1-\beta)\left(t_{2}-\tau_{2}\right)+b\right| \leq b$. Finally, for all $\tau_{2} \geq t_{2}+b /(1-\beta)$

$$
\frac{\partial U_{2}^{\gamma}\left(\tau_{2} \mid t_{2}\right)}{\partial \tau_{2}}=-(1-\beta) k_{2}\left[\ell^{\prime}\left(\left|(1-\beta)\left(t_{2}-\tau_{2}\right)+b\right|\right)-\ell^{\prime}(b)\right] \leq 0 .
$$

This proves that $U_{2}^{\gamma}\left(\tau_{2} \mid t_{2}\right)$ attains a global maximum at $\tau_{2}=t_{2}$.

An analogous argument applies to the case $h^{*}=2$, which is efficient under perfect information as long as $k_{1} \leq k_{2}$.

Q.E.D.

Proof of Proposition 8: Let $d^{*}=\left(d_{1}^{*}, \ldots, d_{k}^{*}, \ldots, d_{n}^{*}\right)$ satisfy (7). Note that each $D_{k}$ has two elements, namely $d_{k}^{*}$ and $d_{k}^{\prime}$. We first show that for each $k$ there exists an $i \in\{1,2\}$ such that $\hat{d}_{k}^{i}=d_{k}^{*}$ satisfies (27). Suppose the contrary. Condition D then implies that 27) must hold for $\hat{d}_{k}^{1}=\hat{d}_{k}^{2}=d_{k}^{\prime}$. Thus, we have for $i=1,2$

$$
u_{i}\left(d_{k}^{\prime} ; d_{-k}\right)>u_{i}\left(d_{k}^{*} ; d_{-k}\right), \text { for all } d_{-k}
$$

In particular, (59) implies that

$$
u_{i}\left(d_{k}^{\prime} ; d_{-k}^{*}\right)>u_{i}\left(d^{*}\right)
$$

for $i=1,2$. Adding the two inequalities in $(60)$ yields $S\left(d_{k}^{\prime} ; d_{-k}^{*}\right)>S\left(d^{*}\right)$, a contradiction to the assumption that $d^{*}$ satisfies (7).

For each $k$ now set $h_{k}=i$ such that $\hat{d}_{k}^{i}=d_{k}^{*}$ satisfies (27). It then follows immediately from (27) that (26) holds for $\left(\hat{d}^{1}, \hat{d}^{2}\right)=d^{*}$. Q.E.D.

Proof of Proposition 9: For $n=1$ Proposition 9 is identical to Proposition 2. To complete the proof we show that Proposition 9 holds for $n$ stages under the presumption that it holds for $n-1$ stages.

Let $d^{*}=\left(d_{1}^{*}, \ldots, d_{k}^{*}, \ldots, d_{n}^{*}\right)$ satisfy $(7)$. Consider the $n-1$ stage subgame after $d_{1}^{*}$ has been chosen in stage 1 . The payoffs in this subgame depend on $d_{-1}=\left(d_{2}, \ldots, d_{n}\right)$ 
according to $u_{1}\left(d_{1}^{*}, d_{-1}\right)-w$ and $u_{2}\left(d_{1}^{*}, d_{-1}\right)+w$, respectively. Therefore $d_{-1}^{*}=$ $\left(d_{2}^{*}, \ldots, d_{n}^{*}\right)$ are the first-best decisions in the $n-1$ stage subgame after $d_{1}^{*}$ has been chosen in stage 1 . Accordingly, for this subgame there exist $h_{-1}^{*}=\left(h_{2}^{*}, \ldots, h_{n}^{*}\right)$ such that $d_{-1}^{*}$ is implemented by a subgame-perfect equilibrium. Note that $D_{1}$ has two elements, namely $d_{1}^{*}$ and $d_{1}^{\prime}$. Let $d_{-1}^{\prime}=\left(d_{2}^{\prime}, \ldots, d_{n}^{\prime}\right)$ denote the decisions that are implemented under $h_{-1}^{*}$ in the $n-1$ stage subgame after $d_{1}^{\prime}$ has been chosen in stage 1.

We will show that there exists some agent $i \in\{1,2\}$ such that this agent will optimally select $d_{1}^{*}$ in the first stage of the $n$ stage game, given that in the remainder of the game the choice of $d_{1}^{*}$ leads to the outcome $d_{-1}^{*}$ and the choice of $d_{1}^{\prime}$ leads to the outcome $d_{-1}^{\prime}$. Suppose the contrary. Then one must have

$$
u_{1}\left(d_{1}^{*}, d_{-1}^{*}\right)<u_{1}\left(d_{1}^{\prime}, d_{-1}^{\prime}\right), \quad u_{2}\left(d_{1}^{*}, d_{-1}^{*}\right)<u_{2}\left(d_{1}^{\prime}, d_{-1}^{\prime}\right) .
$$

This implies $S\left(d^{*}\right)<S\left(d^{\prime}\right)$, a contraction to the assumption that $d^{*}$ satisfies (7).

Thus there is a $h_{1}^{*} \in\{1,2\}$ that induces the choice of $d_{1}^{*}$ in stage 1 and so $h^{*}=\left(h_{1}^{*}, h_{-1}^{*}\right)$ implements $d^{*}$.

Q.E.D.

Proof of Proposition 10: Define $b_{1} \equiv\left|\theta_{11}-\theta_{21}\right|$ and $b_{2} \equiv\left|\theta_{12}-\theta_{22}\right|$. We first show that complementarity of $\left(d_{1}, d_{2}\right)$ implies that

$$
\ell\left(b_{1}, b_{2}\right)<\ell\left(b_{1}, 0\right)+\ell\left(0, b_{2}\right) .
$$

Note that

$$
\int_{0}^{b_{1}} \frac{\partial \ell\left(x, b_{2}\right)}{\partial x} \mathrm{~d} x=\ell\left(b_{1}, b_{2}\right)-\ell\left(0, b_{2}\right), \int_{0}^{b_{1}} \frac{\partial \ell(x, 0)}{\partial x} \mathrm{~d} x=\ell\left(b_{1}, 0\right)-\ell(0,0) .
$$

If $d_{1}$ and $d_{2}$ are complements, then $\partial \ell\left(x, b_{2}\right) / \partial x<\partial \ell(x, 0) / \partial x$ for all $x>0$, and so $\ell(0,0)=0$ and 63 imply 62 .

The payoffs in (30) imply the decisions $d_{k}^{1}=\theta_{1 k}$ and $d_{k}^{2}=\theta_{2 k}$ for $k=1,2$. Therefore

$$
\begin{aligned}
& S\left(d_{1}^{1}, d_{2}^{1}\right)=u_{1}\left(d_{1}^{1}, d_{2}^{1}\right)+u_{2}\left(d_{1}^{1}, d_{2}^{1}\right)=\bar{u}_{1}+\bar{u}_{2}-k_{2} \ell\left(b_{1}, b_{2}\right) \\
& S\left(d_{1}^{2}, d_{2}^{2}\right)=u_{1}\left(d_{1}^{2}, d_{2}^{2}\right)+u_{2}\left(d_{1}^{2}, d_{2}^{2}\right)=\bar{u}_{1}+\bar{u}_{2}-k_{1} \ell\left(b_{1}, b_{2}\right) \\
& S\left(d_{1}^{1}, d_{2}^{2}\right)=u_{1}\left(d_{1}^{1}, d_{2}^{2}\right)+u_{2}\left(d_{1}^{1}, d_{2}^{2}\right)=\bar{u}_{1}+\bar{u}_{2}-k_{1} \ell\left(0, b_{2}\right)-k_{2} \ell\left(b_{1}, 0\right) \\
& S\left(d_{1}^{2}, d_{2}^{1}\right)=u_{1}\left(d_{1}^{2}, d_{2}^{1}\right)+u_{2}\left(d_{1}^{2}, d_{2}^{1}\right)=\bar{u}_{1}+\bar{u}_{2}-k_{1} \ell\left(b_{1}, 0\right)-k_{2} \ell\left(0, b_{2}\right) .
\end{aligned}
$$

Now let $k_{1}>k_{2}$. Then it follows from (64) that

$$
S\left(d_{1}^{1}, d_{2}^{1}\right)>S\left(d_{1}^{2}, d_{2}^{2}\right)
$$


Further by 62 and 64

$$
\begin{aligned}
S\left(d_{1}^{1}, d_{2}^{1}\right)-S\left(d_{1}^{1}, d_{2}^{2}\right) & =k_{1} \ell\left(0, b_{2}\right)+k_{2} \ell\left(b_{1}, 0\right)-k_{2} \ell\left(b_{1}, b_{2}\right) \geq \\
k_{2} \ell\left(0, b_{2}\right) & +k_{2} \ell\left(b_{1}, 0\right)-k_{2} \ell\left(b_{1}, b_{2}\right)>0 .
\end{aligned}
$$

Finally, again by $(62)$ and $(64)$

$$
\begin{aligned}
S\left(d_{1}^{1}, d_{2}^{1}\right)-S\left(d_{1}^{2}, d_{2}^{1}\right) & =k_{1} \ell\left(b_{1}, 0\right)+k_{2} \ell\left(0, b_{2}\right)-k_{2} \ell\left(b_{1}, b_{2}\right) \geq \\
k_{2} \ell\left(b_{1}, 0\right) & +k_{2} \ell\left(0, b_{2}\right)-k_{2} \ell\left(b_{1}, b_{2}\right)>0 .
\end{aligned}
$$

The inequalities in (65)- (67) prove that for $k_{1}>k_{2}$ a contract with $h_{1}=h_{2}=1$ generates the highest surplus. An analogous argument for the case $k_{2}>k_{1}$ completes the proof of the first statement in Proposition 10.

We now turn to the case where $\left(d_{1}, d_{2}\right)$ are substitutes. By the above argument it follows that in this case the inequality in $(62)$ is reversed so that

$$
\ell\left(b_{1}, b_{2}\right)>\ell\left(b_{1}, 0\right)+\ell\left(0, b_{2}\right) .
$$

Suppose that the second statement in Proposition 10 does not hold and that e.g. $h_{1}=h_{2}=1$ is efficient. This is implies $S\left(d_{1}^{1}, d_{2}^{1}\right) \geq S\left(d_{1}^{1}, d_{2}^{2}\right)$ and so by (64)

$$
k_{1} \ell\left(0, b_{2}\right)+k_{2} \ell\left(b_{1}, 0\right) \geq k_{2} \ell\left(b_{1}, b_{2}\right) .
$$

But for $\left|k_{1}-k_{2}\right|$ sufficiently small this yields a contradiction to (68). An analogous argument shows that $h_{1}=h_{2}=2$ cannot be efficient for $\left|k_{1}-k_{2}\right|$ sufficiently small. This proves the second statement in Proposition 10 . Q.E.D. 


\section{References}

Aghion, P. and P. Bolton (1992): "An Incomplete Contracts Approach to Financial Contracting," Review of Economic Studies 59, 473-494.

Aghion, P., M. Dewatripont and P. Rey (2002): "On Partial Contracting," European Economic Review 46, 745-753.

Aghion, P., M. Dewatripont and P. Rey (2004): "Transferable Control," Journal of the European Economic Association 2, 115-138.

Aghion, P. and P. Rey (2003): "Allocating Decision Rights under Liquidity Constraints," in E. Brousseau and J.-M. Glachant (Eds): The Economics of Contracts, Chapter 12, Cambridge University Press.

Aghion, P. and J. Tirole (1997): "Formal and Real Authority in Organizations," Journal of Political Economy 105, 1-29.

Baker, G., R. Gibbons, and K. J. Murphy (1999): "Informal Authority in Organizations," Journal of Law, Economics, and Organization 15, 56-73

Bergemann, D. and J. Välimäki (2002): "Information Acquisition and Efficient Mechanism Design," Econometrica 70, 1007-1033.

Berle, A. A. and G. Means (1932): The Modern Corporation and Private Property, New York: MacMillan.

Bester, H. (2002): "Externalities and the Allocation of Decision Rights in the Theory of the Firm," CEPR Discussion Paper No. 3276.

Bester, H. and R. Strausz (2001): "Contracting with Imperfect Commitment and the Revelation Principle: The Single Agent Case," Econometrica 69, 10771098 .

Bester, H. and R. Strausz (2003): "Contracting with Imperfect Commitment and Noisy Communication," Discussion Paper No. 2003/8, Dept. of Economics, Free University Berlin.

Bolton, P. and A. Rajan (2000): "The Employment Relation and the Theory of the Firm: Arm's Length Contracting vs Authority," Princeton University, mimeo.

Clarke E. (1971): "Multipart Pricing of Public Goods," Public Choice 8, 19-33.

Crawford, V. and J. Sobel (1982): "Strategic Information Transmission", Econometrica 50, 1431-1451. 
Grossman, S. J. and O. Hart (1986): "The Costs and Benefits of Ownership: A Theory of Vertical and Lateral Integration," Journal of Political Economy 94, 691-719.

Dasgupta, P., P. Hammond and E. Maskin (1979): "The Implementation of Social Choice Rules," Review of Economic Studies 46, 185-216.

Dasgupta, P. and E. Maskin (2000): "Efficient Auctions," Quarterly Journal of Economics 115, 341-389.

d'Aspremont, C. and L.A. Gerard-Varet (1979): "Incentives and Incomplete Information," Journal of Public Economics 11, 25-45.

Dessein, W. (2002): "Authority and Communication in Organizations," Review of Economic Studies 69, 811-838.

Gibbard, A. (1973): "Manipulation of Voting Schemes," Econometrica 41, 587-601.

Gibbons, R. (2005): "Four Formal(izable) Theories of the Firm?" Journal of Economic Behavior and Organization 58, 200-245.

Green, J. and J.-J. Laffont (1977): "Characterization of Satisfactory Mechanisms for the Revelation of Preferences," Econometrica 45, 427-438.

Groves, T. (1973): "Incentives in Teams," Econometrica 41, 617-631.

Hart, O. (1995): Firms, Contracts, and Financial Structure, Oxford: Clarendon Press.

Hart, O. and B. Holmstrom (2002): "A Theory of Firm Scope," MIT Department of Economics Working Paper No. 02-42

Hart, O. and J. Moore (1990): "Property Rights and the Nature of the Firm," Journal of Political Economy 98, 1119-1158.

Holmstrom, B. and P. Milgrom (1991): "Multitask Principal-Agent Analyses: Incentive Contracts, Asset Ownership, and Job Design," Journal of Law, Economics, and Organization 7, 24-52.

Jehiel, P. and B. Moldovanu (2001): "Efficient Design with Interdependent Valuations," Econometrica 69, 1237-1259.

Krähmer, D. (2004): "Message Contingent Delegation," Dept. of Economics, Free University Berlin, mimeo, forthcoming in the Journal of Economic Behavior and Organization. 
Krishna, V. and J. Morgan (2004): "Contracting for Information under Imperfect Commitment," Penn State University and University of California at Berkeley, mimeo.

Myerson, R. (1979): "Incentive Compatibility and the Bargaining Problem," Econometrica 47, 61-73.

Myerson, R. (1991): Game Theory, Harvard University Press: Cambridge MA.

Puschke, K. (2005): "The Allocation of Authority under Limited Liability," Dept. of Economics, Free University Berlin, mimeo.

Simon, H. A. (1951): "A Formal Theory of the Employment Relationship," Econometrica 19, 293-305.

Tirole, J. (1999): “Corporate Governance," Econometrica 69, 1-35.

Vickrey, W. (1961): "Counterspeculation, Auctions, and Competitive Sealed Tenders," Journal of Finance 16, 8-37. 